\title{
Issues in Informing Science and Information Technology Volume 16, 2019
}

Edited by Eli B. Cohen

Informing Science Press 
Issues in Informing Science and Information Technology:

Volume 16, 2019

Editor: Eli B. Cohen, Informing Science Institute

Copyright (C) 2019 by the Informing Science Institute. All rights reserved.

(CC BY-NC 4.0) Articles in this journal are licensed to you under a Creative Commons Attribution-NonCommercial 4.0 International License. When you copy and redistribute any of these articles in full or in part, you need to provide proper attribution to it to ensure that others can later locate this work (and to ensure that others do not accuse you of plagiarism). You may (and we encourage you to) adapt, remix, transform, and build upon the material for any non-commercial purposes. This license does not permit you to use this material for commercial purposes.

Published by:

Informing Science Press

131 Brookhill Court

Santa Rosa, California 95409 USA

Telephone: + 1.707.324-3171

Email: Publisher@InformingScience.org

Website: http://InformingSciencePress.com

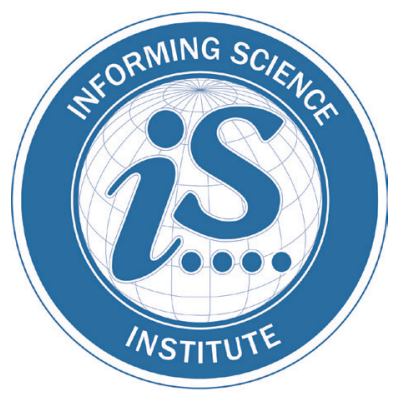

ISBN: 978-1-68110-048-7

ISSN: 1547-9684

Printed in the USA 


\title{
The Journal of \\ Issues in Informing Science and Information Technology
}

\author{
Volume 16, 2019
}

\section{Table of Contents}

How to Program a Chatbot - An Introductory Project and Student Perceptions

Ju Long, Michael Juntao Yuan, Hsun-Ming Lee

Implications of Updating Digital Literacy - A Case Study in an Optometric Curriculum Jo Coldwell-Neilson, James A Armitage, Ryan J Wood-Bradley, Blair Kelly,

Alex Gentle

Fostering Self and Peer Learning Inside and Outside the Classroom through the Flipped Classroom Approach for Postgraduate Students

Eugenia M. W. Ng

Integrating Drone Technology in STEM Education: A Case Study to Assess Teachers' Readiness and Training Needs

Wing Shui Ng, Gary Cheng

Self-efficacy, Challenge, Threat and Motivation in Virtual and Blended Courses on Multicultural Campuses

Revital Cohen, Ilan Daniels Rahimi, Gila Cohen Zilka

Agile Requirements Engineering: An Empirical Analysis and Evidence from a Tertiary Education Context

Meetu Thomas, Mali Senapathi

Assessing the Graphic Questionnaire Used in Digital Literacy Training

Elena Maceviciute, Tom Wilson, Zinaida Manžuch

Factors Influencing Women's Decision to Study Computer Science: Is It Context Dependent?

Sara Genut, Bnaya Ori, Yifat Ben-David Kolikant

Combining Summative and Formative Evaluation Using Automated Assessment

John English, Tammy English

Autoethnography of the Cultural Competence Exhibited at an African American Weekly Newspaper Organization

Erik Bean

Business Priorities Driving BYOD Adoption: A Case Study of a South African Financial Services Organization Jacques Ophoff, Steve Miller

Transition to First Year University Study: A Qualitative Descriptive Study on the Psychosocial and Emotional Impacts of a Science Workshop

Jyothi Thalluri, Joy Penman

Virtually There: The Potential, Process and Problems of Using $360^{\circ}$ Video in the Classroom Sophie McKenzie, Justin Rough, Aaron Spence, Nick Patterson 
Automatic Detection and Classification of Dental Restorations in Panoramic Radiographs

Talia Yeshua, Ya'akov Mandelbaum, Ragda Abdalla-Aslan, Chen Nadler, Laureen Cohen, Levana Zemour, Daniel Kabla, Ori Gleisner, Isaac Leichter ................................. 221-234

Technology in the Classroom: Teachers' Technology Choices in Relation to Content Creation and Distribution

Suzanne Sackstein, Linda Spark, Bryan Turner

The Competencies Required for the BPA Role: An Analysis of the Kenyan Context

Elizabeth Wamicha, Lisa Seymour

Learning Entrepreneurship through Virtual Multicultural Teamwork

Anat Goldstein, Ruti Gafni

Understanding Online Learning Based on Different Age Categories

Danielle Morin, Hamed Safaee, Raafat Saadé ....

Transforming a First-year Accounting Course Using a Blended Learning Pathway

Clara Nkhoma, Mathews Nkhoma, Susan Thomas, Long Ky Tu,

Nha Quoc Le

Emoji Identification and Prediction in Hebrew Political Corpus

Chaya Liebeskind

An Examination of the Barriers to Leadership for Faculty of Color at U.S. Universities

Sydney Freeman Jr., Karen Krier, Ahmed A. Al-Asfour, Russell Thacker ................ 361-376

Grit and Persistence: Findings from a Longitudinal Study of Student Performance

Nicole Buzzetto-Hollywood, Bryant C. Mitchell $377-391$

\section{Review Process}

Except where otherwise noted, all papers were reviewed using a process commonly known as double-blind (that is, with author and affiliation information) by between 6 and 10 external reviewers. The reviewers did not know the identity of the authors nor the authors of the reviewers. Reviewers were matched to papers using a formula to minimize the psychological distance between reviewers' stated expertise and interest and the topics covered in the paper. In cases where this formula did not provide at least 6 reviewers, reviewers were randomly assigned to papers. No reviewer was required to review more than 3 papers.

Reviewers were instructed to mentor the submission's authors by providing feedback on how to improve the submission. They were further required to recommend whether or not the paper should be accepted using a six-point scale (from "reject" to "must accept").

The authors of all papers, whether accepted or not, were provided with the reviewers' feedback as part of our process of mentoring authors. Authors of accepted papers were required to revise their submissions in light of the issues raised in the reviews.

We believe that the papers in this journal represent a great contribution to science. 